Revista Tecné, Episteme y Didaxis: TED. Año 2014, Número Extraordinario. ISSN Impreso: 0121-3814, ISSN web: 2323-0126 Memorias, Sexto Congreso Internacional sobre Formación de Profesores de Ciencias. 08 al 10 de octubre de 2014, Bogotá

\title{
Análise do discurso sobre o currículo presente em um referencial curricular oficial de Química para o ensino médio em Goiás-Brasil
}

Ribeiro Jr'1, Ramon Marcelino, Echeverría², Agustina Rosa

Categoria 2. Trabalho de investigação

\section{Resumo}

Este trabalho tem como foco de investigação o contexto de produção da proposta curricular de Química para o ensino médio em Goiás-Brasil. A análise está fundamentada na abordagem do ciclo contínuo de políticas. Esta abordagem procura mostrar como textos/discursos são criados e recriados numa dinâmica marcada por interpretações em disputa. A análise centrada no contexto de produção permite verificar quais discursos foram privilegiados e quais finalidades sociais estão cumprindo.

\section{Palavras-chave}

Política curricular; Ciclo de Políticas; Ensino médio.

\section{Situando o trabalho}

Este trabalho decorre da nossa participação no processo de produção de um referencial curricular oficial no estado de Goiás - Brasil. Nossa investigação procurou responder quais discursos foram inscritos no texto da proposta curricular. O enfoque teórico-metodológico utilizado foi o ciclo contínuo de políticas (Ball, 1994).

Como resultados de um movimento nacional de reformas curriculares, o estado de Goiás fez um movimento de reforma do ensino médio entre 2008 e 2010. Essa reforma não escapou ao reducionismo que marca as políticas curriculares. Suas propostas se resumiam a questões curriculares como a implantação da semestralidade, a oferta de disciplinas optativas e a produção de documentos curriculares disciplinares. Participamos da produção do referencial de Química. O documento final foi fruto de 18 reuniões de uma equipe composta por professores da universidade e da rede escolar estadual.

1 Instituto Federal de Goiás; ramon0201@hotmail.com

2 Universidade Federal de Goiás; agustina@brturbo.com.br 
Revista Tecné, Episteme y Didaxis: TED. Año 2014, Número Extraordinario. ISSN Impreso: 0121-3814, ISSN web: 2323-0126 Memorias, Sexto Congreso Internacional sobre Formación de Profesores de Ciencias. 08 al 10 de octubre de 2014, Bogotá

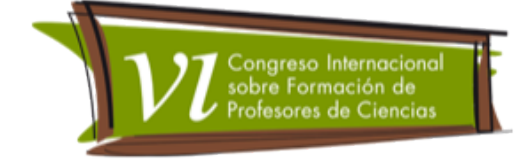

O processo não transcorreu sem conflitos. Participamos desse processo na tríplice condição de professor da rede estadual, aluno de mestrado e co-autor da proposta (Ribeiro Jr, 2012).

O propósito específico da nossa comunicação é apresentar o discurso sobre a concepção curricular presente no contexto de definição dos textos da proposta.

\section{Abordagem teórico-metodológica}

Nos apoiamos para a realização da investigação na abordagem do ciclo continuo do políticas que permite apreender a dinâmica e complexidade dos processos de negociação que geram a política curricular. Essa, concebida como fruto da articulação entre três contextos: de influência, onde as definições e os diversos discursos são iniciados ou construídos; de produção dos textos/discursos, onde os documentos são elaborados; e da prática: onde os textos/discursos são reinterpretados, em diferentes níveis, gerando mudanças na política inicial (Abreu, 2010, pág. 29).

A política é constituída por um processo complexo a perpassar e ser perpassado por múltiplos contextos em que inevitavelmente estão em jogo diferentes demandas de diferentes sujeitos, individuais ou coletivos. Esses disputam espaços para instituir suas perspectivas a respeito das finalidades educacionais, das formas de conceber e organizar um currículo sintonizado com essas finalidades, bem como dos modos de interpretação das disciplinas escolares e concepções sobre o papel dos professores.

A política é configurada simultaneamente como textos/discursos. Em sua dimensão textual destacamos os processos de interpretação e reinterpretação, numa palavra, as múltiplas leituras a que estão sujeitas como artefatos culturas significativos. Já sua dimensão discursiva permite entendermos a indissociabilidade entre o material e o simbólico, entre o verbal e o não verbal, e sobre como os significados e sentidos por nós produzidos e privilegiados não espelham simplesmente o mundo em si, mas constroem versões particulares do mundo atravessadas por relações de poder.

Ao investigar os discursos que constituem a política procuramos as regras que orientam as práticas. Em relação ao referencial curricular em questão elaboramos como pergunta estruturante da pesquisa: quais e como são construídos os principais discursos que compõem/constituem as reuniōes de 
Revista Tecné, Episteme y Didaxis: TED. Año 2014, Número Extraordinario. ISSN Impreso: 0121-3814, ISSN web: 2323-0126 Memorias, Sexto Congreso Internacional sobre Formación de Profesores de Ciencias. 08 al 10 de octubre de 2014, Bogotá

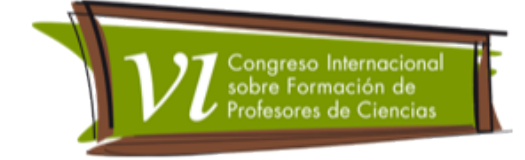

\section{concepção (contexto de definição) do referencial curricular de química para o ensino médio do estado de Goiás?}

Durante $O$ processo de elaboração do documento foram gravadas e transcritas cinco reuniões (R1, R2, R3, R4 e R5), caracterizadas como "reuniões de concepção". Participamos dessas reuniões sobre a tríplice condição de professor da rede estadual, autor da proposta e da investigação sobre a proposta. Para identificação dos autores das falas analisadas criamos as seguintes legendas: as professoras formadoras são PF1, PF2, PF3, PF4; As professoras que atuam na rede estadual e também são alunas do Mestrado em Educação em Ciências e Matemática da Universidade Federal de Goiás são: PREM 1, Ramon e PRE é professora da rede estadual. Pela tríplice condição acima referida, me identifico explicitamente.

Durante o desenvolvimento da pesquisa emergiram como principais discursos constitutivos da proposta: 1) Finalidades do ensino de química; 2) Concepção de currículo; 3) Critérios de seleção e organização dos conteúdos. Elegemos para esta comunicação a apresentação do discurso sobre a concepção de currículo.

\section{Discurso sobre as concepções de currículo}

A concepção foi tratada de modo direto e sua configuração foi assim delineada

112 (R2) Ramon - Bom, é a proposta curricular. Então acho que a gente poderia dizer o que é o currículo pra gente, como a gente entende esse currículo e é importante ter nesse currículo, o que é fundamental. Como o texto é pra ser um texto simples, eu acho importante algumas coisas ficarem explicitas, por exemplo, ponto um: o currículo não é lista de conteúdos. Nós temos que pontuar isso, temos que deixar isso claro pra eles. Ponto dois: existem diferentes formas de se organizar o currículo. É importante superar, romper ou pelo menos entender que a organização por frentes, que é uma terminologia muito usada nas escolas, não é a única forma de organizar o currículo.

113 (R2) PF1 - Organização por?

114 (R2) PREM1 - Frentes. Orgânica, geral, físico-química.

115 (R2) Ramon - É. Eu coloquei por frentes, eu tô lançando mão de um vocabulário bem difundido entre os professores nas 
Revista Tecné, Episteme y Didaxis: TED. Año 2014, Número Extraordinario. ISSN Impreso: 0121-3814, ISSN web: 2323-0126 Memorias, Sexto Congreso Internacional sobre Formación de Profesores de Ciencias. 08 al 10 de octubre de 2014, Bogotá

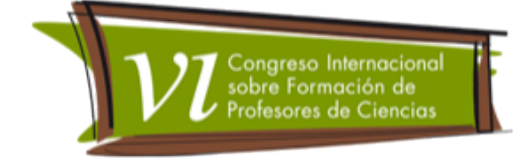

escolas, ou seja, a distinção tradicional entre físico-química, geral e orgânica é uma não a única... Eu acho importante dizer isso. As orientações até deixam isso claro, eles falam: "Olha, conectar, evitar essa.

116 (R2) PREM1 - Essa fragmentação.

Como a ideia de que o currículo se resume a uma lista de conteúdos é amplamente aceita entre os professores ela é o primeiro alvo dos autores porque eles defendem que o currículo não é lista de conteúdos. Como uma das características já referidas do ensino de química atual é a sequência rígida, linear e fragmentada dos conteúdos, sobretudo conforme sua disposição em livros didáticos convencionais, a ideia de que há diferentes formas de se organizar o currículo é defendida como capaz de contribuir para romper com tal estado de coisas. Os autores ilustram a crítica referindo-se a divisão entre química geral, físico-química e química orgânica hegemônica na maioria dos livros didáticos destinados ao ensino médio e como aporte para sua crítica recorrem ao documento oficial nacional que quanto a esse assunto deixam isso claro. O texto referido são as Orientações Curriculares Nacionais para o Ensino Médio (Brasil, 2006).

O entendimento dos autores é de que se faz necessário desenvolver um texto simples, de linguagem acessível, que não se constitua em tarefa demasiado árdua para a leitura dos professores. Ainda que a referência seja ao que é importante ter no currículo, podemos compreender que isso dirá o que o currículo é. O que o currículo é será dado pelo conjunto de predicados que Ihe serão atribuídos.

Outro aspecto constituinte do conceito desenvolvido pelos autores é o seu caráter de construção social e negociada e representando um "território contestado" onde há conflitos de interesses e disputas de poder.

117 (R2) Ramon - Dizer que o currículo é negociado e construído socialmente, ou seja, é fundamentalmente um campo de conflito, de disputa de interesses. É a expressão de uma política cultural. Que na construção do currículo, nós vamos considerar... $\mathrm{E}$ é importante que o professor sempre considere também quando ele for montar sua proposta tanto parâmetros históricosociais, quanto epistemológicos. Ele tem que pensar na questão social.

Ao reconhecer e afirmar que o currículo apresenta essas características os autores se situam no espaço da teorização crítica do currículo. O currículo é 
Revista Tecné, Episteme y Didaxis: TED. Año 2014, Número Extraordinario. ISSN Impreso: 0121-3814, ISSN web: 2323-0126 Memorias, Sexto Congreso Internacional sobre Formación de Profesores de Ciencias. 08 al 10 de octubre de 2014, Bogotá

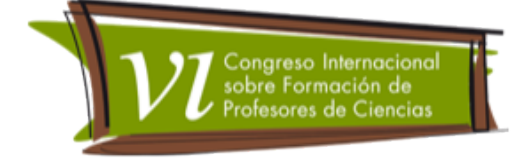

uma construção social, e não um dado natural. Seus significados são construídos nas relações sociais, entendidas como relações de produção de significados que serão não só diferentes, mas conflitantes em virtude do caráter desigual que constitui essas mesmas relações sociais. Assim, os conflitos, as tentativas de manutenção ou alteração da ordem social se expressarão no currículo.

Ligado a essas características está a historicidade do currículo e, decorrente dessa, seu caráter dinâmico.

135 (R2) Ramon - Então essa questão do currículo, não só do conhecimento, mas do próprio currículo ser dinâmico e histórico.... O currículo de química hoje é fruto de uma evolução, não de uma evolução no sentido de progresso, mas no desenvolvimento histórico. Era diferente, antigamente e pode ser diferente no futuro, e a gente espera que seja diferente pra melhor, não é isso? Não é neutro, não é neutro. Quando a gente faz o currículo a gente se posiciona, assume uma visão de sociedade, uma visão de escola, uma visão de aluno, uma visão de mudo que vai defender, e por isso vai propor o currículo dessa e dessa forma.

Em cada momento histórico do desenvolvimento de uma sociedade são travadas disputas em torno da significação dos conceitos de cultura e conhecimento. Dessas disputas vão resultar as definições do que conta como cultura e conhecimento dessas esferas maiores, o que tem relevância para a instituição escolar, ou seja, aquilo que pode ser levado para a escola constituindo a cultura e o conhecimento escolares. O currículo é tomado como não neutro, ou seja, será resultado de posicionamentos políticos. Posição essa que ganha o detalhamento na sequência

141 (R2) PREM1 - E outra coisa que eu acho importante. Está incluído nesse currículo a concepção de homem e sociedade... Significa que o professor quando assume não fazer esse currículo, não pensar esse currículo, ele não está tomando posse, ela não está assumindo a sua condição de educador, não está assumindo, não se posiciona... É uma coisa não deliberada. Ele está formando, ele está reproduzindo uma ideia de forma não deliberada. Então tem que deixar claro que essa atuação docente, essa atuação educativa que cabe também ao professor, precisa ser deliberada, precisa deixar seus objetivos claros. 
Revista Tecné, Episteme y Didaxis: TED. Año 2014, Número Extraordinario. ISSN Impreso: 0121-3814, ISSN web: 2323-0126 Memorias, Sexto Congreso Internacional sobre Formación de Profesores de Ciencias. 08 al 10 de octubre de 2014, Bogotá

142 (R2) PF1 - É se eles deixam de fazer não estão sendo neutros. Ele está seguindo o que outros pensaram.

143 (R2) PREM1 - Isso. Se ele não pensa, ele manda outro. Ele está reproduzindo sem saber.

144 (R2) PF1 - É. Que significa que o professor pegue o índice do livro e dê a química daquilo. O que significa aquilo?

145 (R2) Ramon - De certo modo, ele está assumindo as concepções...

146 (R2) PF1 - Ele pode não ter refletido, primeiro porque não foi formado pra isso, ai também não vamos jogar a culpa no professor. Temos que dizer que ele não foi formado para aquilo lá. E eu sei isso porque eu estou fazendo essa discussão de livro didático no estágio 2. "Qual a visão de ciência que está nesse livro?". Então é ai que começamos a identificar visões que estão nas entrelinhas. Então: o professor não é formado pra isso. Mas quando o professor pega aquele livro didático e segue ele pode estar pensando assim: "há, eu estou cheio de aula, muita coisa pra fazer, e eu vou fazer do jeito que está." Ai poderia até achar que está sendo neutro. Não está. Está de uma forma irrefletida assumindo a postura que outros tiveram quando escreveram aquilo. E isso mesmo?

\section{Considerações finais}

O discurso analisado apresenta características de uma concepção crítica de currículo. Os autores não desconhecem as limitações que a formação da maioria dos professores tem. No entanto elas não são tomadas como motivo para excluir os professores desse poder e responsabilidade e sim como demonstrando a necessidade de que esses professores recebam formação para tal, que sejam estimulados e apoiados para qualificar seu pensamento em torno das questões educacionais em geral e do currículo em particular. Essa postura é coerente com a defesa que o grupo faz da concepção de professores reflexivos (Maldaner, 2000). Os autores defendem que a questão "o que é o currículo?" precisa ser objeto de estudo e investigação pelos professores apoiados por uma discussão teórica que possibilite a ampliação da autonomia relativa que lhe é concedida para trabalhar com os conteúdos com que ele "realmente vai querer trabalhar durante o ano". 
Revista Tecné, Episteme y Didaxis: TED. Año 2014, Número Extraordinario. ISSN Impreso: 0121-3814, ISSN web: 2323-0126

Memorias, Sexto Congreso Internacional sobre Formación de Profesores de Ciencias. 08 al 10 de octubre de 2014, Bogotá

\section{Referências bibliográficas}

Abreu, R. G. (2010) A comunidade disciplinar de ensino de Química na produção de políticas curriculares para o ensino médio no Brasil. Tese de doutorado, Universidade do Estado do Rio de Janeiro, Rio de Janeiro.

Ball, S. J. (1994) Education Reform: a critical and post-structural approach. Buckingham: Open University Press.

Brasil (2006) Orientações Curriculares para O Ensino Médio. Secretaria da Educação Básica. Ministério da Educação, Brasília.

Goiás (2010). Química: referencial curricular para o ensino médio. Goiânia: Editora Formato.

Maldaner, O. A. (2000) A formação inicial e continuada de professores de Química: professores/pesquisadores. ljuí: Editora Unijui.

Ribeiro Jr, R. M. (2012) Análise do contexto de produção do texto de um referencial curricular oficial de Química para o ensino médio em Goiás. Dissertação de mestrado, Universidade Federal de Goiás, Goiânia. 